\title{
El asalto al Trocadero y la invasión de los Cien Mil Hijos de San Luis en Cádiz
}

\author{
FÁTIMA SALAVERRY BARO
}

Tras producirse la invasión del territorio español por los Cien Mil Hijos de San Luis, el 7 de abril de 1823, las tropas francesas pudieron avanzar por España, con la excepción de algunas plazas fortificadas. No hay que olvidar que el gobierno en aquellos momentos, ante la llegada de los franceses a Madrid, a Córdoba y a otros puntos, fue desplazándose hacia el sur, donde decidieron como medida de precaución que las Cortes y el Poder Ejecutivo se trasladaran hacia Cádiz; al negarse Fernando VII a abandonar Sevilla, donde se encontraban en aquellos momentos, las Cortes lo declararon incapaz y se nombró una Regencia que ejerció el poder durante su viaje a Cádiz, donde de nuevo se le habilitó en sus funciones.

El 16 de agosto de aquel mismo año el duque de Angulema llegó al sur de Andalucía, permaneciendo ante Cádiz sin poder dar un paso adelante, a pesar del superior contingente de tropas que dirigía.

Ante tal circunstancia, decidió el ataque del Trocadero, de gran importancia porque era uno de los principales fuertes para la defensa de Cádiz, ya que debido a su posición estratégica y cercanía, desde allí se podía bombardear la ciudad. En esta zona, otro punto defensivo lo constituía el castillo de Fort-Louis, lugar importante para la defensa del puerto interior.

Desde un primer momento, tanto para la defensa como para el ataque del Trocadero se tomaron medidas por parte de ambos contingentes. Si por parte de los Cien Mil Hijos de San Luis se requirió una "trabajosa operación preparatoria consistente en la apertura de trincheras que posibilitasen el avance de las tropas francesas hasta las posiciones españolas, evitando la descrubierta en un terreno tan abierto y desprovisto de 
obstáculos naturales» (1), de igual forma ocurrió en las tropas nacionales, pues para éstas, la defensa del Trocadero no estuvo exenta de dificultades.

Todo el proceso de defensa provocó toda una serie de medidas más o menos trascendentes, pero que influyeron decisivamente en la vida cotidiana de los gaditanos durante el asedio. Por ejemplo, una de las primeras medidas tomadas por las autoridades fue pedir a los habitantes de Cádiz 300 rejass de hierro, que se tomarían de los edificios públicos, conventos o de cualquier otra parte y que se pondrían a disposición del Comandante militar de la plaza, y que serían abonadas por la Comisión de Depositaría, cargándose a cuenta de las contribuciones. De las rejas pedidas sólo se consiguieron 128; ante esta situación se publicó una invitación dirigida a los propietarios particulares, para que proporcionaran las de sus casas, e incluso se llegó a dar la orden de que, si el número no se completaba hasta las 300 rejas, se quitarían las que fuesen necesarias.

Como el envío no fue suficiente para las necesidades del ejército ello obligó al general en jefe del Ejército de Reserva Antonio Burriel a solicitar una nueva remesa. Junto a esta medida también se procedió al alquiler de vigas para la defensa del Trocadero.

Por otra parte, se ordenó requisar todos los caballos y monturas de Cádiz e incluso de San Fernando; con este motivo el Ayuntamiento de la ciudad, a petición del general en jefe del Ejército de Reserva, acordaba que: (2)

- La comisión de requisación la formarían los señores Marichalar, Guisasola y Aruela.

- Se sortearían por esta comisión dos individuos para el reconocimiento y aprecio de los caballos.

-Que inmediatamente se publicaran edictos señalando el día 29 de agosto de 1823 para la presentación de todos los caballos en el picadero del Callejón de la Cerrería (3).

-Y, por último, se pedía consultar a la Diputación Provincial si el valor de los caballos se tenía que satisfacer del importe de contribuciones, o a dónde habría que recurrir a fin de contestar a los interesados: finalmente fue la comisión de Hacienda la encargada de ejecutar el pago.

(1) R. SÁNCHEZ MANTERO, "Los Cien Mil Hijos de San Luis y las relaciones francoespañolas». Sevilla, 1981, p. 77.

(2) Archivo Municipal de Cádiz (A.M.C.). Actas Capitulares (A.C.), 1823, fol. 576.

(3) Este acuerdo se realizó el día 27 de agosto de 1823. 
Otras muchas disposiciones fueron tomadas por la ciudad. Un bando dictado por las autoridades militares, con objeto de aumentar las filas del ejército constitucional, establecía que aquellos vecinos y habitantes que no pertenecieran a la Milicia Nacional fueran llamados por los alcaldes de los barrios para que se presentaran ante ellos, fijándose las penas en las que incurrían los que "en cualquier caso de alarma o de ataque promoviesen desorden, diesen voces o formasen reuniones» (4). También la Comisión de Reemplazo y Milicias se encargó de aumentar los batallones de voluntarios, por medio de una invitación al vecindario. Con similar intención fue el plan ideado por el jefe de Policía, en el que se establecía la formación de un cuerpo de vecinos que se encargaran de conservar; durante un ataque o alarma, el orden y la tranquilidad interior del pueblo. Incluso en los pueblos de la provincia de Cádiz se establecieron listas de voluntarios que en caso de necesidad pasarían al servicio de guerra.

No quedó prohibido el tráfico con los pueblos inmediatos a la capital. Aunque el general en jefe del Ejército de Reserva estableció una distinción por sexos y quedaron excluidos los militares, en un intento de preservar la población masculina para un posible ataque del enemigo.

A'demás se prohibió en Cádiz todo toque de campana y se estableció que las bombas y demás útiles de apagar incendios se pusiesen en buen estado de uso.

Para combinar los medios de defensa de la plaza y proporcionar aquellos que faltasen fue creada una Junta, que estuvo compuesta por el gobernador, comandante de Artillería y de Ingenieros, un comandante del batallón de la guarnición, otro de la Milicia Nacional y por dos individuos del Ayuntamiento.

La Junta tuvo por objeto oír todos los proyectos de obras de defensa, proveer todos los pedidos de los gobernadores o comandantes de las fuerzas o líneas, así como los medios de realizarlos.

Al aumentar la posibilidad de bombardeo que tenía la ciudad y la necesidad de tener expeditos los edificiós, el gobernador solicitó al Ayuntamiento que le diese noticias de los que estaban a su disposición, de los que se podían desocupar y, asimismo del motivo por el que no se podía proceder a la evacuación de otros.

Entre las numerosas disposiciones que se tomaron no todas fueron relativas sólo a Cádiz, sino que también se aplicaron en su provincia. En estos casos la Milicia se dividiría en dos clases: la que haya de per-

(4) A.M.C., A.C., 1823, fol., 572. 
manecer en sus lugares y la que se presente para hacer el servicio de guerra. Con anticipación se tomarían noticias y conocimientos de ambas y, la primera, al acercarse al enemigo debía recoger las armas y depositarlas en un paraje seguro para que pudiera disponer de éstas el ejército. Con respecto a la segunda, se formaría una columna militar, que sirviendo de apoyo, ejecutaría las órdenes y movimientos que dispusiesen los generales de los ejércitos.

Para las obras de defensa se convocó todos los albañiles, carpinteros y herreros, a los que les pagaban diariamente sus jornales, pues existía el temor de que su incumplimiento llegase a paralizar las obras. Fueron proporcionados trece o catorce buques de setenta pies de quilla para sumergirlos en las bocas de algunos caños, cien fornituras y cartucheras y la construcción de lanchas cañoneras, para la defensa de la línea española. También se creó una Brigada compuesta de todos los pilotos, pilotines, contramaestres y demás hombres de mar.

Durante los trabajos defensivos que realizaban ambos bandos no se abandonó la lucha; de manera que Adolfo de Castro (5) recuerda como el 16 de julio de 1823, entre las seis y siete de la mañana, se produjo un encuentro que duró "medio cuarto de hora" y en el que se tuvo que pactar con el comandante francés de la línea para suspender las hostilidades y retirar del campo los cadáveres y heridos.

Pero el verdadero asalto al Trocadero tuvo lugar a fines de agosto de 1823. El ejército constitucional conocía la estrategia del enemigo, consistente en construir delante de la Cortadura que separaba a ambos bandos una trinchera, así como un puente para atravesarla.

El plan de las tropas francesas era el siguiente:

Una vez que concluyeron las trincheras, las utilizarían, como señala Sánchez Mantero (6), para pasar hacia las posiciones enemigas, y una vez allí atacar al enemigo por la derecha, mientras las tropas iban sumándose a la contienda por medio de un puente sobre la Cortadura.

Desde el primer momento la confusión estuvo presente en el ejército español, pues creía que la invasión de sus posiciones se produciría por el flanco izquierdo. Esta creencia se apoyaba en el hecho de que era contra esta zona donde se abría fuego. Sin embargo, los franceses invadieron el flanco derecho, pasando de noche en medio de un gran silencio, cundiendo en el bando constitucional el desorden y la confusión.

(5) "Historia del Trocadero y Matagorda". Cádiz, 1896, p. 194.

(6) "Los Cien Mil Hijos de San Luis $y$ las relaciones franco-españolas", Sevilla, 1981, pp. 77-78. 
Hay una descripción poética de la pérdida del Trocadero escrita por un entusiasta liberal: (7)

«Escuchad, escuchad los valerosos defensores del vasto Trocadero, los males, los peligros y la muerte miraban siempre con igual desprecio. Tres días há que en vigoroso ataque temblando tributaba el extranjero a nuestro ardor innumerables vidas, y tres días también que el dulce sueño de nosotros huía. Era la hora en que el astro de luz su rojo fuego en lo profundo del Océano oculta. Cesa el combate: los caudillos nuestros la línea de defensa reconocen: "entregaos al reposo sin recelo" gritan los enemigos aterrados, tiemblan tanto valor. Tales acentos las intrépidas almas tranquilizan. Cedimos jay! al apacible sueño. Pero que despertar tan horroroso: Nunca españoles duermen los guerreros; los cobardes esclavos, que no osaran presentarse en la lid a campo abierto de la traición bajo el inícuo manto penetran en el fuerte. Sus aceros nos despiertan, nos hieren: la defensa inútil fuera ya: Los astilleros al aplicar las encendidas mechas, o detenidos por la espalda o muertos, el bronce abrazan por la vez postrera. El jefe ilustre que con noble esfuerzo quiere reunir al trémulo soldado cobardemente herido muerde el suelo. Todo ya es confusión, grita, desorden. Cercados por do quiera, recorremos, sin plan, sin guía la mansión de la muerte.

(7)' A. CASTRO, "Historia del Trocadero $y$ Matagorda». Cádiz, 1896, pp. 214-215. 
En el fango hundidos hasta el pecho esgrimen unos la tajante espada, otros se arrojan al Océano inmenso, porque al morir a esclavitud prefieren... viérais allí, españoles, al guerrero luchar con vida amarga, ya elevarse sobre su cima, ya en el hondo seno sumergirse del mar, ya resecado por la onda con vigor, perder aliento y hallar sepulcro en el profundo abismo. Soldados viérais despreciando el riesgo batirse sólo contra cien esclavos, y el corazón por inclemente acero traspasado, batirse todavía.

Valor inútil. ¡Malhadados tiempos! Héroes infortunados. Dulce patria. Ahí todo se acabó: fatales hierros ¡cadenas, servidumbre, oprobio, muerte sólo te aguardan infelice pueblo...!».

Una vez que Angulema tomó el Trocadero, se dirigió hacia Chiclana de la Frontera, donde los constitucionales se rindieron inmediatamente, y posteriormente a la Isla de León para iniciar aquí su ataque y con ello centrar su acción contra Cádiz. Así pues, se siguieron las tareas defensivas, con medidas tales como la de prohibir que se proporcionase pasaporte para salir de la península gaditana a ningún varón que fuese apto para contribuir a la defensa común, o facultades para proporcionar medios para ella.

Al iniciar el ataque a la Isla de León, Angulema supo que el rey había sido puesto en libertad por los constitucionales. En principio, una manifestación popular impidió al monarca dirigirse a El Puerto de Santa María; sin embargo, finalmente pudo ser recibido en esta ciudad por el duque de Angulema, una vez que concedió a los manifestantes las garantías de seguridad que éstos solicitaban.

Con el Real Decreto dado por Fernando VII el 2 de octubre de 1823, se produjo la entrega de los ejércitos constitucionales establecidos en esta zona. Este Real Decreto decía así:

"Restituido en la plenitud de mis reales derechos, no descansara mi real ánimo hasta que alcancen a mis amados vasallos los efectos de tan fausto acontecimiento y a este fin he venido en resolver, que se entreguen en el día de mañana todos los puestos militares de la Isla 
de León y de la plaza de Cádiz, al ejército que manda mi augusto y amado primo el duque de Angulema, para que las ocupe en mi real nombre a cuyo fin dispondréis lo conveniente -l oficio iba dirigido al general en jefe del Ejército de Reserva--, para que se pongan de acuerdo los jefes militares de dichos puestos con los del mismo ejército aliado. Lo traslado a Vuestra Ecelencia para su conocimiento y el de el Ayuntamiento de esa ciudad, manifestándole que he dado las órdenes para que tenga cumplimiento la anterior real resolución" (8).

\section{APÉNDICE}

Armamento, fornituras y municiones recogidas del $6 .^{\circ}$ Batallón de la Milicia Nacional Voluntaria (9).

\begin{tabular}{lccccccc}
\hline Fusiles & Bayonetas & Cartucheras & $\begin{array}{c}\text { Correas de } \\
\text { éstas }\end{array}$ & Portasables & Cartuchos & Balas \\
\hline 632 & 626 & 482 & 495 & $\cdots$ & 497 & 3.689 & 1.979
\end{tabular}

Armamento, fornituras y municiones recogidas del $4 .^{\circ}$ Batallón de la Milicia Nacional Voluntaria (10).

\begin{tabular}{|c|c|c|c|c|c|}
\hline Fusiles & Bayonetas & Cartucheras & $\begin{array}{l}\text { Correajes de } \\
\text { éstas }\end{array}$ & Portafusiles & $\begin{array}{c}\text { Cartuchos y } \\
\text { balas }\end{array}$ \\
\hline 484 & 480 & 629 & 610 & 34 & 1.554 \\
\hline
\end{tabular}

Armamento recogido de los Batallones de la Milicia Local (11).

Fusiles con bayonetas

Fusiles sin bayonetas

Cartucheras sin correas

Correas para cartucheras

Portabayonetas

(8) A.M.C., A.C., 1823, fols. 656-657.

(9) Ibídem, fol. 335.

(10) Ibídem, fol. 333 .

(11) Ibídem, fol. 338 . 
Portafusiles

Cartuchos embalados para fusil español .......................... 7.725

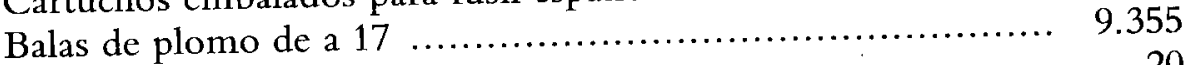

Tercerolas ..................................................... 20

Sables para caballería .......................................... 20

Espadas para caballería ......................................... 13

Armamento recogido de las seis compañías pertenecientes al $2 .^{\circ} \mathrm{Ba}-$ tallón de la Milicia Local de Cádiz (12).

\begin{tabular}{cccccc}
\hline Compañía & $\begin{array}{c}\text { Fusiles y } \\
\text { bayonetas }\end{array}$ & Correas & Cartucheras & Cartuchos & Balas \\
\hline Granaderos & 92 & 164 & 78 & 110 & 69 \\
$1{ }^{2}$ Comp. & 89 & 144 & 73 & 91 & 101 \\
$2 .{ }^{2}$ Comp. & 75 & 130 & 64 & 97 & 114 \\
$3{ }^{3}$ Comp. & 100 & 146 & 76 & 210 & 69 \\
4. ${ }^{2}$ Comp. & 112 & 164 & 76 & 136 & 00 \\
Cazad. & 89 & 170 & 87 & 106 & 96 \\
\hline TOTAL & 557 & 918 & 454 & 750 & 449
\end{tabular}

Resumen del armamento recogido de las seis compañías que componían el Primer Batallón de la Milicia Nacional V. Realizado por José Monet, comandante accidental de la plaza (13).

\begin{tabular}{cccccc}
\hline Compañías & $\begin{array}{c}\text { Fusiles } \\
\text { completos }\end{array}$ & $\begin{array}{c}\text { Fusiles sin } \\
\text { bayonetas }\end{array}$ & Cartucheras & $\begin{array}{c}\text { Correajes de } \\
\text { cartucheras }\end{array}$ & Portasables \\
\hline Granaderos & 98 & & 94 & 88 & 88 \\
1 1. Fusileros $^{\circ}$ & 112 & 2 & 86 & 91 & 91 \\
${ }^{\circ}$ Fusileros & 98 & & 86 & 86 & 86 \\
$3{ }^{\circ}$ Fusileros & 85 & & 93 & 68 & 68 \\
$4 .{ }^{\circ}$ Fusileros & 88 & & 72 & 77 & 77 \\
Cazadores & 115 & & 96 & 90 & 92 \\
\hline TOTAL & 596 & 2 & 527 & 500 & 502
\end{tabular}

(12) Ibídem, fol. 331.

(13) Ibídem, fol. 330. 